\title{
A Comparison between Drifter and X-Band Wave Radar for Sea Surface Current Estimation
}

\author{
Giovanni Ludeno ${ }^{1, *}$, Carmelo Nasello ${ }^{2}$, Francesco Raffa ${ }^{3}$, Giuseppe Ciraolo ${ }^{2}$, \\ Francesco Soldovieri ${ }^{1}$ and Francesco Serafino ${ }^{4}$ \\ 1 Institute for Electromagnetic Sensing of the Environment, National Research Council, 80124 Napoli, Italy; \\ soldovieri.f@irea.cnr.it \\ 2 Department of Civil, Environmental, AeroSpace, Materials Engineering, University of Palermo, \\ 90128 Palermo, Italy; carmelo.nasello@unipa.it (C.N.); giuseppe.ciraolo@unipa.it (G.C.) \\ 3 Institute for Coastal Marine Environment, National Research Council (CNR-IAMC), 98122 Messina, Italy; \\ francesco.raffa@iamc.cnr.it \\ 4 Institute of Biometeorology of the National Research Council (CNR-IBMET), I-50145 Firenze, Italy; \\ serafino.f@irea.cnr.it \\ * Correspondence: ludeno.g@irea.cnr.it; Tel.: +39-81-762-0653; Fax: +39-81-570-5734
}

Academic Editors: Raffaele Persico, Xiaofeng Li, Deepak R. Mishra and Prasad S. Thenkabail Received: 28 June 2016; Accepted: 17 August 2016; Published: 24 August 2016

\begin{abstract}
This paper deals with exploitation of the wave radar system for sea surface current estimation in a coastal zone. In particular, we present the results of the processing of the radar data collected by an X-band marine radar installed in Capo Granitola site, which is located in the south-west part of Sicily, on 15 May 2015. The effectiveness of the data processing is analyzed by comparing the wave radar estimated sea surface current with that provided by the Lagrangian drifters along its movement trajectory. During the measurement campaign, three drifter releases are carried out and for each one the comparison is provided in terms of the mean error and standard deviation. In addition, we report the characteristic sea state parameters, in terms of peak wavelength $\left(\lambda_{\mathrm{p}}\right)$, peak direction propagation $\left(\theta_{\mathrm{p}}\right)$, peak period $\left(T_{p}\right)$ and significant wave height $\left(H_{\mathrm{s}}\right)$ of the dominant waves estimated by the wave radar system.
\end{abstract}

Keywords: marine X-band radar; sea state monitoring; sea surface current estimation; Lagrangian drifters

\section{Introduction}

Monitoring of wind, sea waves and sea surface current is more challenging in coastal areas, because of the interaction among these factors on smaller spatial scales with respect to the case of open sea. For this reason, in a coastal environment the sea state parameters as well as the sea surface currents are challenging to measure with the accuracy and spatial resolution requested by the relevant applications.

A first class of sea surface current measurements is based on drifters, which are able to provide information about their movement trajectory. The exploitation of drifters is an effective way to perform sea surface velocities measurement. Acoustic Doppler Current Profiler (ADCP) or Acoustic Doppler Velocimeter (ADV) instruments are generally used for this kind of measures. The ADCP measures are not precise in the cells below the sea surface (first meter), due to the ultrasonic reflection at the interface air-sea. On the other hand, the ADV measures refer to a fixed point, but it is very difficult to keep the instrument stationary in a prefixed location of the sea.

The position of a drifter can be inferred from the Doppler-based Argos tracking, or from satellite GPS System [1]. In the literature, two classes of drifters are used to measure the surface current in the oceans: with and without drogues [2]. The Surface Velocity Program (SVP) and the Coastal Ocean 
Dynamics Experiment (CODE) drifters are examples of drifters with and without drogues, respectively. The SVP has a subsurface holey-sock drogue centered at $15 \mathrm{~m}$ nominal depth [3,4]. CODE system measures coastal currents in the first meter below the ocean surface [5,6]. Very recently, a new small drifter prototype has been developed to measure the current in the first $25 \mathrm{~cm}$ below the free surface. A first validation of this prototypal drifter was concerned with the harbor area of Trieste, Italy $[7,8]$ during different field campaigns. Unfortunately, drifters are not able to achieve spatially continuous measurements over time into a specific area.

A second class of sea surface current measurements is based on X-band marine radar, which is able to perform sea state monitoring close to the coast and estimate the surface currents (intensity and direction) with very high spatial and temporal resolution, in a maximum range of about $5 \mathrm{~km}$ from radar platform. Several strategies have been implemented in order to estimate the surface current from the 3D image spectrum as the basic least-squares (LS) fitting technique [9], the weighted LS method [10], the iterative LS (ILS) approach [11], the dispersive surface classificator (DiSC) method [12], and Polar Current Shell (PCS) algorithm [13]. In this context, the authors have developed the normalized scalar product (NSP) procedure [14]. The surface current estimation by NSP has already been tested by means the comparison with coastal HF radar observations [15,16], which has demonstrated the good performance of the X-band radar system in estimating sea state and surface currents.

The novelty of the present work resided in the comparison, at our knowledge for the first time in literature, between X-band radar and Lagrangian drifter measurements for the surface current estimation. The analysis has been carried out in the Strait of Sicily, where the surface current estimation is relevant for the upwelling phenomenon detection. The comparison is provided in terms of the mean error and standard deviation for each drifter's release; finally, we evaluate the total mean error percentage for the overall comparison.

Therefore, the paper is organized as follows. In Section 2, we give a brief description of the instrumentation and the methodologies deployed to acquire and to process the data for the surface current estimation in Capo Granitola site. The comparison between the estimated currents provided by the X-band radar and drifter measurements is presented in Section 3. In Section 4 the analysis of results is presented. Finally, conclusions end the paper.

\section{Test Site, Instrumentation and Methodologies}

This section is devoted at describing the test site, the instrumentations and the related data processing approaches used for the sea surface current monitoring. We carried out the comparison between the wave radar system and the drifter at Capo Granitola site, which is located in the south-west part of Sicily and washed by the Mediterranean Sea (see Figure 1). This area of the Mediterranean Sea has a significant biodiversity and is affected by several complex oceanographic processes. Therefore, the information about the sea state parameters and surface currents is important: to safeguard the biodiversity; to forecast the coastal erosion; to support decisions for the crisis events related to oil spill phenomenon.

The details of the instrumentation and data processing approach are reported in the following subsections. 


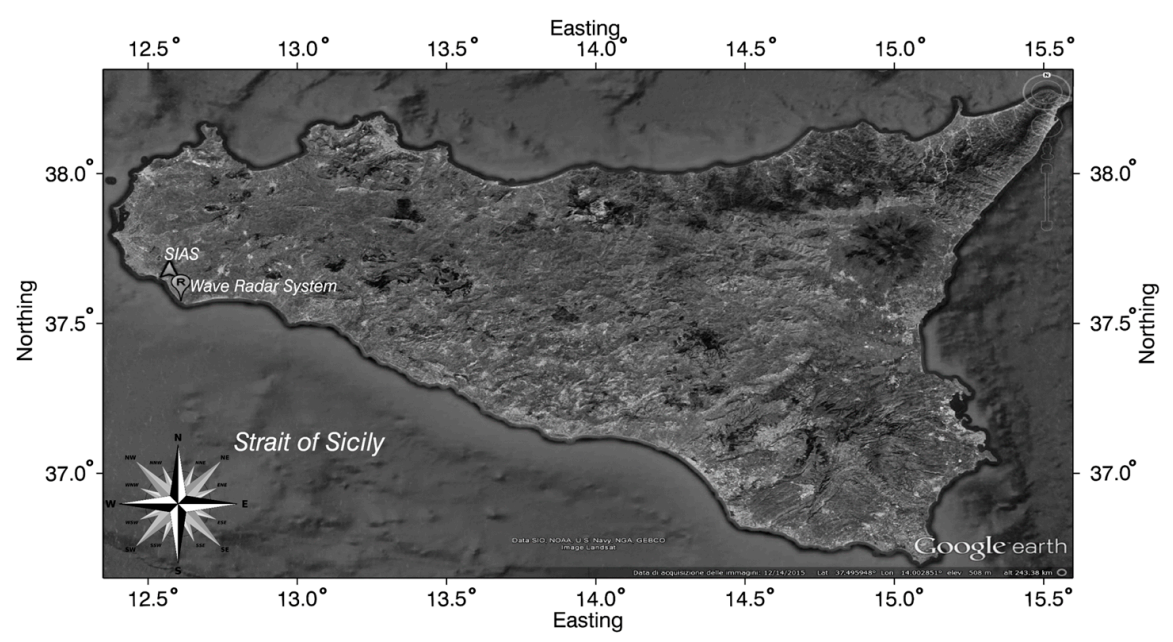

Figure 1. Point (R) and the triangle indicate the position of the wave radar system in Capo Granitola site and the meteorological station of the network Servizio Informativo Agrometeorologico Siciliano (SIAS), respectively.

\subsection{Drifters}

The drifters used for the experiment have a truncated-conical shape, with a maximum diameter (at the top) of $0.35 \mathrm{~m}$ and height of $0.27 \mathrm{~m}$ (see Figure 2). They are equipped with GPS satellite system, radio modem, recording memory and battery. Each trajectory point has been sampled approximately every 1 min by the GPS system (GPS coordinates in UTM WGS84 format), recorded and transmitted via radio to the operator, with an overall position error smaller than two meters (WAAS corrected). Two drifters were released three times in different zones of the area investigated by the X-band radar, and kept in the water as long they remained within the wave radar observation field.

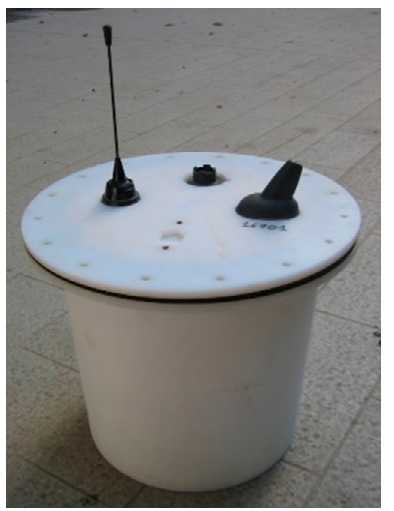

Figure 2. Drifter with GPS and radio antenna equipped.

The measurements occurred during about $2 \mathrm{~h}$ duration on 15 May 2015 and during the experiment, the sea wave height was lower than $1.0 \mathrm{~m}$. A first drifter was released (R1) from 12:31 (UTC) to 13:28. The drifter recorded 25 GPS positions (trajectory length $2500 \mathrm{~m}$ ) when it moved towards the North-West (Figure 3). Every velocity R1 is the average of 2-3 GPS velocities inside the same radar cell with $225 \mathrm{~m}$ size. The same drifter was used for a second release (R2) from 13:42 (UTC) to 14:46. The drifter recorded 23 GPS positions (trajectory length $2380 \mathrm{~m}$ ) and it moved towards the North-West. The drifter velocities R2 are the average of 1-3 GPS velocities for a fixed radar cell of $225 \mathrm{~m}$. Another drifter was used for the third release (R3) from 13:44 (UTC) to 14:48, almost at the same time of R2 release; the drifter recorded 62 GPS positions (trajectory length $2510 \mathrm{~m}$ ) and it moved towards the North-West. The drifter velocities $\mathrm{R} 3$ are the average of 4-5 GPS positions. 




Figure 3. Red, green and yellow lines are the trajectories of the releases R1, R2, R3, respectively. The drifters moved towards the North-West.

The three trajectories are similar because the drifters were released in a narrow time range of about $2 \mathrm{~h}$. The minimum and maximum distances between the drifters and the radar are $1200 \mathrm{~m}$ and $2350 \mathrm{~m}$, respectively.

\subsection{Wave Radar System}

The radar images are not the direct representation of the sea surface since a number of distortions, known as modulation effects, are introduced during the radar imaging process. Indeed, the radar echo is rather tied to the slope of the long waves (tilt modulation) and to the roughness of the riding ripples (hydrodynamic modulation) $[17,18]$. In addition, radar signals also suffer the shadowing phenomenon, according to which no information can be received from sea surface areas that are not in line of sight [17-19].

On the basis of the previous considerations, the data processing is formulated as an inversion problem and is based on the use of the dispersion relation between wave motion, surface current and sea depth.

$$
\omega(\bar{k})=\sqrt{g k \tanh (k h)}+\bar{k} \cdot \bar{U}
$$

that defines the $\omega-k$ (spectral) domain where the sea energy concentrates. In Equation (1) $\bar{k}=\left(k_{x}, k_{y}\right)$ represents the wave vector (whose amplitude $k=2 \pi / \lambda$ is the wave number, $\lambda$ being the wavelength), $\omega$ is the angular frequency related to the wave period $T$ by $\omega=2 \pi / T, g$ represents the acceleration due to gravity, $h$ is the sea depth and $\bar{U}=\left(U_{x}, U_{y}\right)$ is the vector representing the sea surface current. Determination of velocity and direction of surface current by wave radar system is performed analyzing the three-dimensional (3-D) wave number/frequency spectrum, which is obtained by performing 3-D Fast Fourier Transform (FFT) of the radar images sequence [9].

In order to take into account the spatial non-uniformity of the surface current and bathymetry, several improved "local" inversion procedures have been developed [12,20-23]. Herein, we adopt the "Local Method" based on the Normalized Scalar Product (NSP) [14,16,20,22,23]. NSP method is based on the maximization of the normalized scalar product between the amplitude of the radar spectrum, here denoted by $\left|F_{I}(\bar{k}, \omega)\right|$ and the characteristic function:

$$
G(\bar{k}, \omega, \bar{U}, h)=\delta(\omega-\sqrt{g k \tanh (k h)}-\bar{k} \cdot \bar{U})
$$


accounting for the support of the dispersion relation. Accordingly, the NSP estimates $\hat{U}$ of the surface currents arise from the following equation:

$$
\hat{U}=\underset{\bar{U}}{\operatorname{argmax}} \frac{\left|F_{I}(\bar{k}, \omega)\right|, G(\bar{k}, \omega, \bar{U}, h)}{\sqrt{P_{F} \cdot P_{G}}}
$$

where $\left|F_{I}(\bar{k}, \omega)\right|, G(\bar{k}, \omega, \bar{U}, h)$ denotes the scalar product between the functions $F_{I}(\cdot)$ and $G(\cdot)$, having a power equal to $P_{F}$ and $P_{G}$, respectively. It is worth noting, that the NSP method allows us, in principle, the joint estimation of the surface current and bathymetry values. In this work, we assume an a priori information about the sea depth, which was gained during a previous measurements campaign. The knowledge of the surface current and bathymetry values allow us to build on the basis of the dispersion relation the Band Pass filter, which is applied to the image spectrum $F_{I}(\bar{k}, \omega)$; the result of the filtering is the function $\widetilde{F}_{I}(\bar{k}, \omega)$. To obtain the characteristic sea state parameters is needed to turn from the filtered radar image spectrum to the sea wave spectrum. This step requires the knowledge of the radar modulation transfer function (MTF), which accounts for the specific modalities of the electromagnetic sensing phenomenon [24]; in this study case, we adopt the MTF already used for the sea state monitoring in the coastal area in front of Giglio Island (coastal area) [22].

More details about the procedure for the surface current estimation close to coastal area through the NSP method and the retrieval of the characteristic sea state parameters can be found in $[16,20,22,24]$.

The radar deployed for the measurements is a Consilium X-band radar equipped with a 9 feet ( $2.7 \mathrm{~m}$ ) long antenna and able to transmit a peak power of $25 \mathrm{~kW}$ with $\mathrm{HH}$ polarization. The radar is installed in the Capo Granitola harbor on a building at a height of $15 \mathrm{~m}$ above sea level and located at the coordinates: $\mathrm{LAT}=37^{\circ} 34^{\prime} 19.40^{\prime \prime} \mathrm{N} ; \mathrm{LON}=12^{\circ} 39^{\prime} 33.43^{\prime \prime} \mathrm{E}$. The nautical radar was connected to the data processing and visualization unit, which incorporates an analog-to-digital (AD) converter for the received signal.

The images were stored using a 13-bit unsigned integer format, on a $1024 \times 1024$ pixels Cartesian grid. The radar images were acquired in the temporal interval of about two hours covering the drifters' releases. In particular, eighteen radar datasets (each dataset consists of 32 images covering 77 seconds duration) were acquired each five minutes and after analyzed. Therefore, 18 surface current fields were obtained for our analysis. The details of the radar acquisition parameters are summarized in Table 1.

Table 1. Measurements parameters of the wave radar system.

\begin{tabular}{cc}
\hline Radar Parameters & Value \\
\hline Antenna rotation period $(\Delta t)$ & $2.39 \mathrm{~s}$ \\
Spatial image spacing $(\Delta x$ and $\Delta y)$ & $4.5 \mathrm{~m}$ \\
Minimum range & $200 \mathrm{~m}$ \\
Maximum range & $2296 \mathrm{~m}$ \\
Image number for sequence $\left(N_{s}\right)$ & 32 \\
Antenna height above sea level & $\sim 15 \mathrm{~m}$ \\
View angular sector & $\sim 135^{\circ}$ \\
\hline
\end{tabular}

Figure 4 shows two samples of radar images of the investigated area and the estimated surface current fields on a square mesh size of $225 \mathrm{~m}$. 

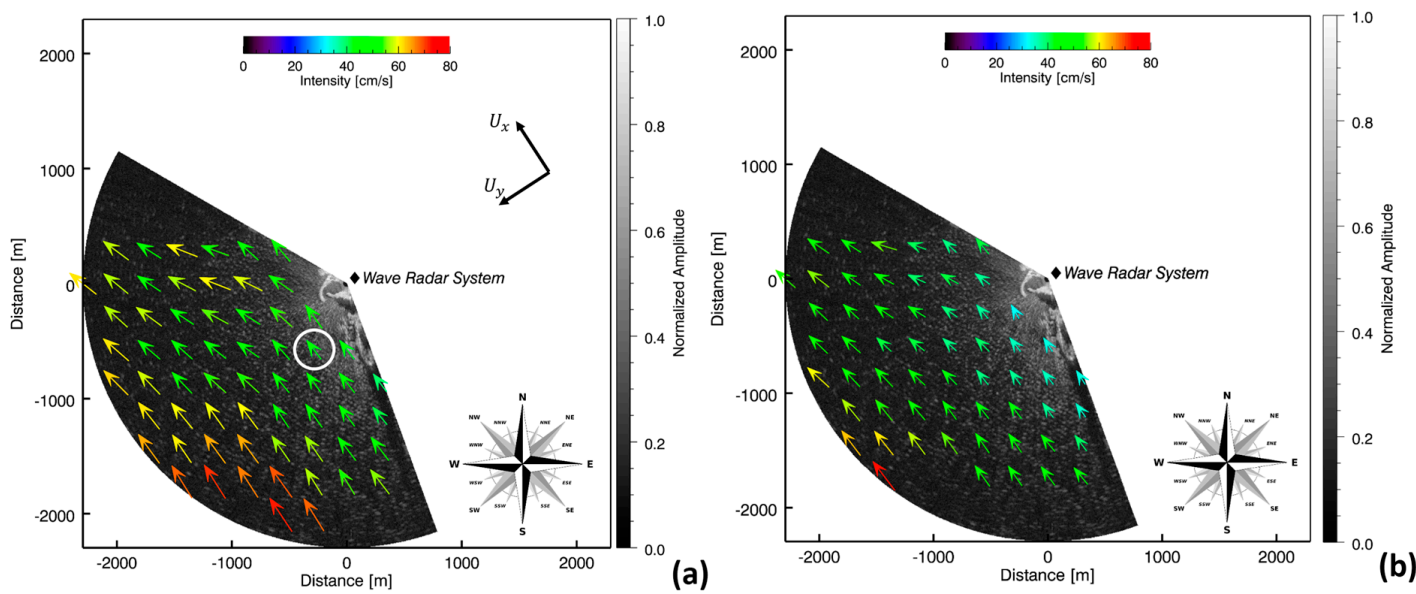

Figure 4. Radar image with over plotted the surface current field estimated during the measurement campaign on 15 May 2015. (a) Surface current field at 13:00 UTC; (b) Surface current field at 14:00 UTC.

As can be observed in Figure 4, the estimation of the sea surface current is missing on the lateral areas of the radar image due to the lower sea state condition, which does not permit to have accurate data for a reliable estimation.

\section{Results}

This section provides the results of the comparison between the drifter and wave radar system in terms of velocity and direction of the estimated sea surface current. In this measurement campaign, the surface currents are generated by wind and their patterns are determined by wind direction. The wind parameters have been computed by the meteorological station of the network SIAS (Servizio Informativo Agrometeorologico Siciliano) of Mazara del Vallo (TP), at about $13 \mathrm{~km}$ from the area investigated in this work (see Figure 1). Winds prevalently blew from SE-SSE as reported in Table 2.

Table 2. Wind parameters during the measurements campaign.

\begin{tabular}{cccc}
\hline Day & Time Survey & Wind Speed $(\mathbf{m} / \mathbf{s})$ & Wind Direction $(\mathbf{d e g})$ \\
\hline 15 May 2015 & $12: 00$ & 4.2 & 176 \\
15 May 2015 & $13: 00$ & 7.1 & 155 \\
15 May 2015 & $14: 00$ & 5.9 & 177 \\
\hline
\end{tabular}

The comparison between the measurements has been done at a scale (mesh size equal to $225 \mathrm{~m}$ ) where the radar estimations are reliable. The results of the comparison of the surface current velocity and direction are shown in Figure 5a,b, respectively. 


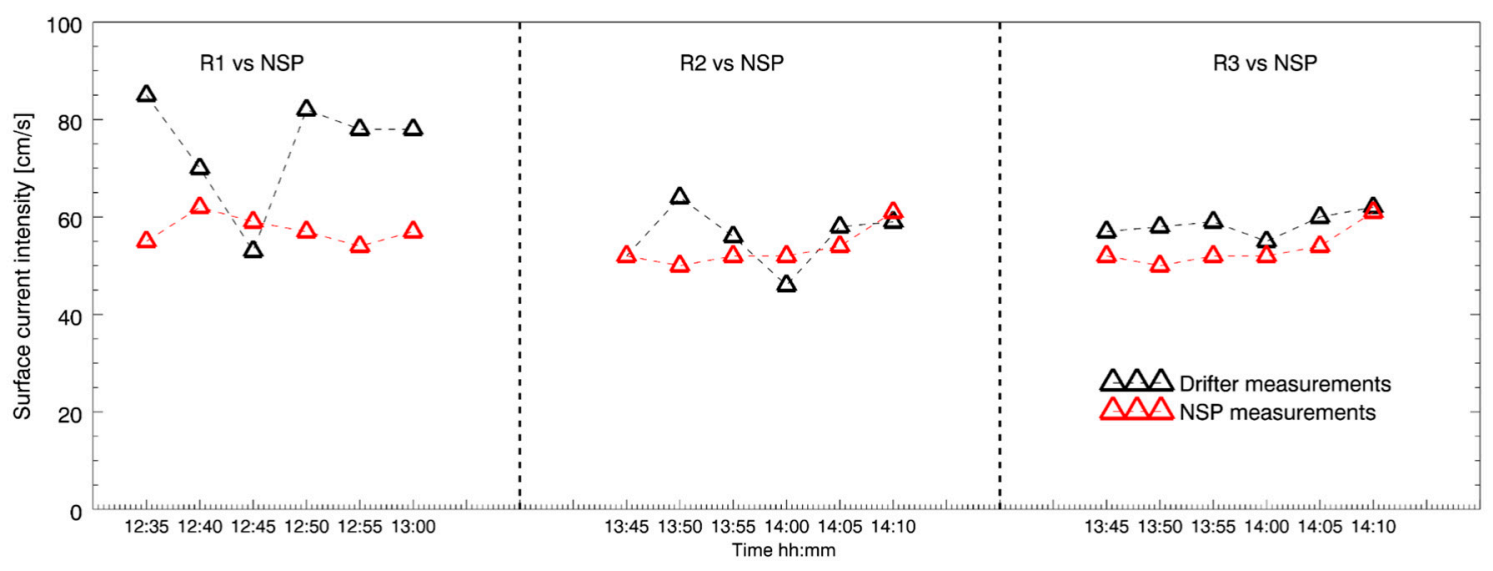

(a)



(b)

Figure 5. Comparison between the measurements of surface current by means wave radar (red triangle) and drifters (black triangle). (a) Comparison of the surface current intensity; (b) Comparison between surface current directions.

\section{Discussion}

As shown in Figure 5a, the velocities (intensities) estimated by the drifter are generally higher than the ones measured by the wave radar. In particular, the larger differences in sea surface current velocity occur for the release 1 (R1), where the corresponding mean error is $18 \mathrm{~cm} / \mathrm{s}$ (percentage error $30 \%$ ), whereas for the releases R2 and R3 the mean error is equal to 2 and $5 \mathrm{~cm} / \mathrm{s}$ (percentage error $4 \%$ and $9 \%$ ), respectively. The standard deviation of release $\mathrm{R} 1$ is equal to $12 \mathrm{~cm} / \mathrm{s}$, larger than the other two R2 and R3. There is an evident decrease of the velocity along the trajectory for R1 release. Probably this decrease is due to a temporary low number of connected satellites in GPS system, rather than the presence of a particular wave period or circulation structures, which are not detectable by the other drifter releases. In Table 3 the surface currents provided by drifters, in term of velocity and direction, are indicated with $U_{D}$ and $\theta_{D}$, respectively, whereas $U_{R}$ and $\theta_{R}$ represent the same quantities retrieved through the radar system. We observe that all the measurements provide the indication of a current moving toward the north-west. The error on the estimates surface current direction ranges from $5 \%$ to $+8 \%$. 
Table 3. Statistical analysis in terms of the mean values standard deviation and mean error percentage.

\begin{tabular}{|c|c|c|c|}
\hline & \multicolumn{3}{|c|}{ R1 } \\
\hline & MeanValues & Std. & Mean Error \\
\hline$U_{\mathrm{D}}[\mathrm{cm} / \mathrm{s}]$ & 75 & 12 & \multirow{2}{*}{$30 \%$} \\
\hline$U_{\mathrm{R}}[\mathrm{cm} / \mathrm{s}]$ & 57 & 3 & \\
\hline$\theta_{\mathrm{D}}[\mathrm{deg}]$ & 311 & 3 & \multirow{2}{*}{$5 \%$} \\
\hline \multirow[t]{3}{*}{$\theta_{\mathrm{R}}[\mathrm{deg}]$} & 305 & 3 & \\
\hline & \multicolumn{3}{|c|}{$\mathbf{R} 2$} \\
\hline & Mean Values & Std. & Mean Error \\
\hline$U_{\mathrm{D}}[\mathrm{cm} / \mathrm{s}]$ & 56 & 6 & \multirow[b]{2}{*}{$4 \%$} \\
\hline$U_{\mathrm{R}}[\mathrm{cm} / \mathrm{s}]$ & 54 & 4 & \\
\hline$\theta_{\mathrm{D}}[\mathrm{deg}]$ & 320 & 3 & \multirow{2}{*}{$6 \%$} \\
\hline \multirow[t]{3}{*}{$\theta_{\mathrm{R}}[\mathrm{deg}]$} & 312 & 3 & \\
\hline & \multicolumn{3}{|c|}{ R3 } \\
\hline & Mean Values & Std. & Mean Error \\
\hline$U_{\mathrm{D}}[\mathrm{cm} / \mathrm{s}]$ & 59 & 2 & \multirow{2}{*}{$9 \%$} \\
\hline$U_{\mathrm{R}}[\mathrm{cm} / \mathrm{s}]$ & 54 & 4 & \\
\hline$\theta_{\mathrm{D}}[\mathrm{deg}]$ & 322 & 1 & \multirow{2}{*}{$8 \%$} \\
\hline$\theta_{\mathrm{R}}[\mathrm{deg}]$ & 312 & 3 & \\
\hline
\end{tabular}

In addition, the wave radar system provides the characteristic sea state parameters, in term of peak wavelength $\left(\lambda_{\mathrm{p}}\right)$, peak direction propagation $\left(\theta_{\mathrm{p}}\right)$, peak period $\left(T_{p}\right)$ and significant wave height $\left(H_{\mathrm{s}}\right)$ of the dominant waves. Here, we report two directional spectra provided by the wave radar system during the measurement campaign. In particular, Figure $6 \mathrm{a}, \mathrm{b}$ depict the directional spectra evaluated on the beginning (at 12:40 UTC) and the end (at 14:05 UTC) of the measurement campaign, respectively.
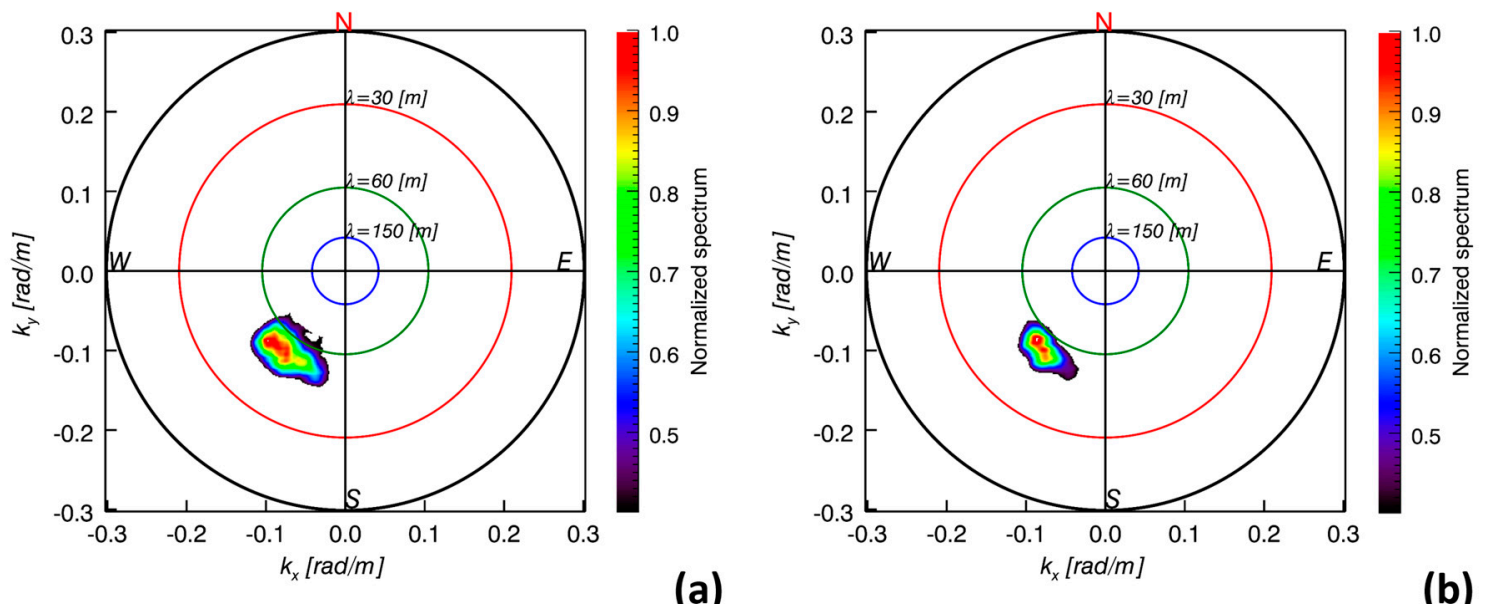

Figure 6. Directional spectra provided by the wave radar system during the measurement campaign on 15 May 2015. (a) directional spectrum at 12:40 UTC; (b) directional spectrum at 14:05 UTC.

It worth noting, that the radar images have been acquired in sea state condition of "gentle breeze" with low significant wave height $\left(H_{s}\right)$ smaller than $1 \mathrm{~m}$ (level 3 on Beaufort scale) as reported in Table 4 . This low significant wave height is a challenging condition for the surface current estimation by means of the radar system. 
Table 4. Sea state parameters provided by the wave radar system during the measurement campaign on 15 May 2015.

\begin{tabular}{cccccc}
\hline & \multicolumn{5}{c}{ Time UTC } \\
\hline & $\mathbf{1 2 : 4 0}$ & $\mathbf{1 2 : 5 0}$ & $\mathbf{1 2 : 5 5}$ & $\mathbf{1 3 : 4 5}$ & $\mathbf{1 4 : 0 5}$ \\
\hline $\boldsymbol{H}_{\boldsymbol{s}}[\mathrm{m}]$ & 0.6 & 0.6 & 0.7 & 0.6 & 0.6 \\
$\boldsymbol{T}_{\boldsymbol{p}}[\mathbf{s}]$ & 6.2 & 6.1 & 6.1 & 6.1 & 6.2 \\
$\lambda_{\mathbf{p}}[\mathrm{m}]$ & 60 & 59 & 59 & 58 & 60 \\
$\boldsymbol{\theta}_{\mathbf{p}}[\mathrm{deg}]$ & 215 & 214 & 214 & 215 & 210 \\
\hline
\end{tabular}

Let us turn now to discuss about the reliability of the sea surface current estimations here reported. As it can be noted from Figures 4 and 6, the peak direction of the sea wave propagation (about 215 degrees) is quasi-orthogonal to the direction of the surface current (about 310 degrees) estimated by NSP and almost similar to the one predicted by drifter measurements. This means that the scalar product $\bar{k} \cdot \bar{U}$ of Equation (1) is close to zero, but actually, thanks to a wide spectrum spreading (about 30 degrees for the directional spectra shown in Figure 6), the NSP method is still able to provide an reliable surface current estimation. Therefore, an explanation is in order to evaluate and justify the accuracy of the sea surface current estimated by NSP in this challenging condition.

In particular, for the discussion here presented, we consider the estimations obtained from the sub-area at the coordinate points $x=-287 \mathrm{~m}$ and $y=-574 \mathrm{~m}$ highlighted by the white circle in Figure $4 \mathrm{a}$.

Figure 7a shows the NSP function for $U_{x}$ and $U_{y}$ values varying in the interval $[-200 \mathrm{~cm} / \mathrm{s}$, $200 \mathrm{~cm} / \mathrm{s}$ ] and it can be noted how the NSP is less sensitive to the variation of $U_{x}$ with respect to the ones along $U_{y}$. This is justified by a physical point of view by accounting for that the radar is able to collect more accurate information about the sea waves coinciding with the range (y-axis). In other words, the estimation of the pair of surface current components suffer a more pronounced ill-conditioning for the $U_{x}$ values.
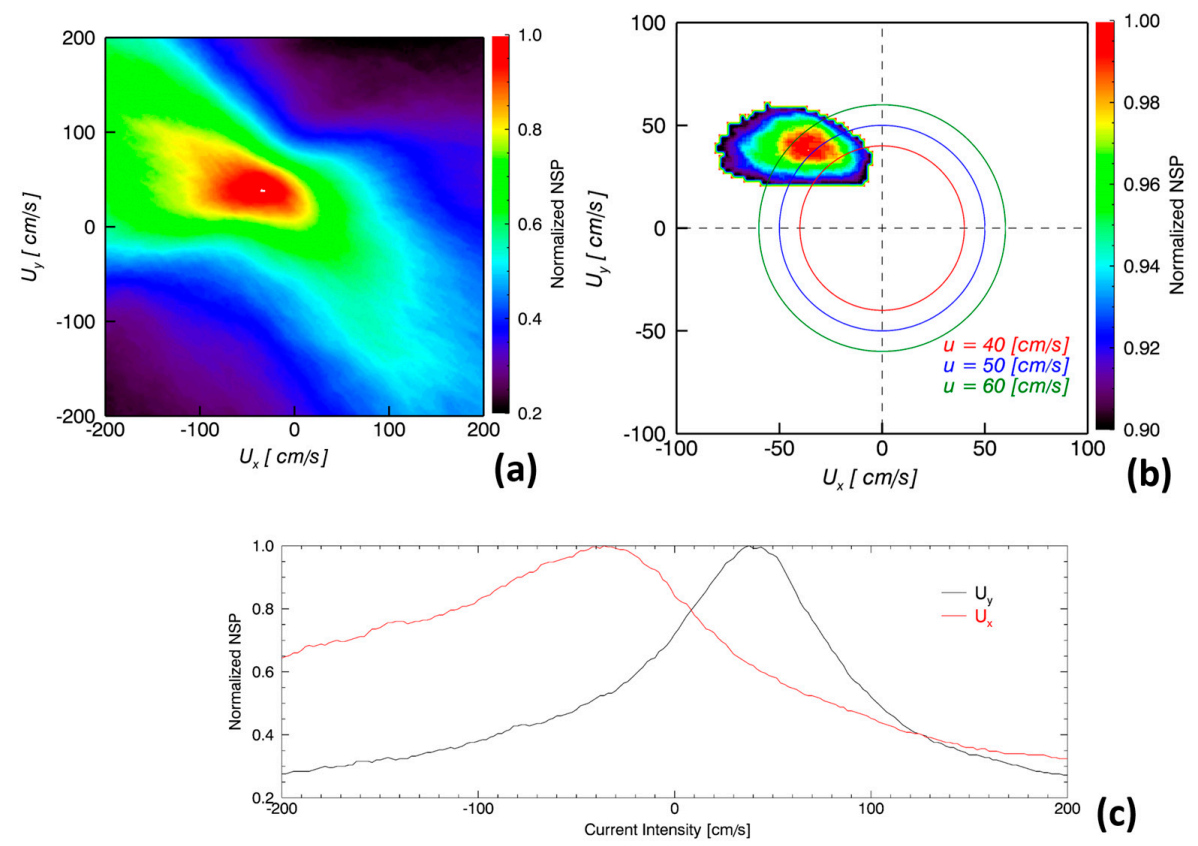

Figure 7. (a) Normalized scalar product (NSP) functional obtained by varying $U_{x}$ and $U_{y}$ components in the interval [ $-200 \mathrm{~cm} / \mathrm{s}, 200 \mathrm{~cm} / \mathrm{s}]$; (b) NSP functional with values greater than $90 \%$ in the interval $[-100 \mathrm{~cm} / \mathrm{s}, 100 \mathrm{~cm} / \mathrm{s}]$ and with overlapped three circles with radius equal to $40 \mathrm{~cm} / \mathrm{s}, 50 \mathrm{~cm} / \mathrm{s}$ and $60 \mathrm{~cm} / \mathrm{s}$; (c) The behavior of the NSP Functional along the two current components passing through the estimated value $U_{x}=-36 \mathrm{~cm} / \mathrm{s}, U_{y}=38 \mathrm{~cm} / \mathrm{s}$. 
Figure $7 \mathrm{~b}$ shows the NSP functional with values greater than $90 \%$ and from this figure it can be noted that the amplitude of the sea surface current ranges from 50 to $60 \mathrm{~cm} / \mathrm{s}$. In order to have a more quantitative evaluation of the amplitude of the sea surface current, we can evaluate the centroid of this spot, which provides the values $\left(U_{x}=-46 \mathrm{~cm} / \mathrm{s}, U_{y}=38 \mathrm{~cm} / \mathrm{s}\right)$. The centroid values are close to the ones of the maximum of the NSP $\left(U_{x}=-36 \mathrm{~cm} / \mathrm{s}, U_{y}=38 \mathrm{~cm} / \mathrm{s}\right)$, which provides $|U|=52.3 \mathrm{~cm} / \mathrm{s}$. Figure 7c shows the behavior of the NSP functional along the two current components passing through the estimated values $\left(U_{x}=-36 \mathrm{~cm} / \mathrm{s}, \mathrm{U}_{\mathrm{y}}=38 \mathrm{~cm} / \mathrm{s}\right)$.

\section{Conclusions}

This paper has presented a comparison regarding the estimation of sea surface current from data collected by wave radar system and drifters. Experimental results showed that the X-band radar equipped with NSP data processing method provided results in a good agreement with the ones given by the drifters' releases. In addition, wave radar system was able also to provide information about sea state parameters in terms of wavelength, direction, period and significant wave height. The values of significant wave height, about $0.6 \mathrm{~m}$, confirmed the low level of the sea state, which is a challenging situation for the surface current estimation. Furthermore, a discussion about the reliability of the NSP estimation performance, in this challenging situation, has been provided with the focus on the sensitivity of the NSP with respect to the two different (vector) components of the sea surface current. The main conclusion of this work is that the wave radar system can be considered a reliable tool for the sea state parameters estimations during wave motion by providing continuous measurements over time, which is not possible for the drifter technology.

Acknowledgments: The research activity leading to this paper has been performed within the framework of the RITMARE Flagship Project, funded by the Italian Ministry of University and Research. The Authors express sincere appreciation to Gaspare Buffa, IAMC-CNR UOS Capo Granitola, for having supported the experimental activities.

Author Contributions: Giovanni Ludeno, Francesco Raffa and Francesco Soldovieri took care of the radar data and carried out the experiments. Carmelo Nasello took care of the drifters measurements. Giuseppe Ciraolo and Francesco Serafino supervised the work. Giovanni Ludeno has also the leadership in writing the paper and assimilating the data in the approach. Accordingly, Giovanni Ludeno can be considered the first author of this paper.

Conflicts of Interest: The authors declare no conflict of interest.

\section{References}

1. Poulain, P.M.; Bussani, A.; Gerin, R.; Jungwirth, R.; Mauri, E.; Menna, M.; Notarstefano, G. Mediterranean surface currents measured with drifters: From basin to sub inertial scales. Oceanography 2013, 26, 38-47. [CrossRef]

2. Pazan, S.E. Intercomparison of drogued and undrogued drift buoys. In Proceedings of the MTS/IEEE Oceans'96 Conference, Fort Lauderdale, FL, USA, 3-26 September 1996.

3. Paduan, J.D. Wind-Driven motions in the northeast pacific as measured by lagrangian drifters. J. Phys. Oceanogr. 1995, 25, 2819-2830. [CrossRef]

4. Lumpkin, R.; Pazos, M. Measuring surface currents with SVP drifters: The instrument, its data and some results. In Lagrangian Analysis and Prediction of Coastal and Ocean Dynamics; Griffa, A., Kirwan, J.A.D., Eds.; Cambridge University Press: Cambridge, UK, 2007; pp. 39-67.

5. Davis, R.E. Drifter observation of coastal currents during CODE: The method and descriptive view. J. Geophys. Res. 1985, 90, 4741-4755. [CrossRef]

6. Manning, J.P.; McGillicuddy, D.J.; Pettigrewc, N.R.; Churchill, J.H.; Incze, L.S. Drifter observations of the Gulf of Maine Coastal Current. Cont. Shelf Res. 2009, 29, 835-845. [CrossRef]

7. Petronio, A.; Roman, F.; Nasello, C.; Armenio, V. Large eddy simulation model for wind-driven sea circulation in coastal areas. Nonlinear Process. Geophys. 2013, 20, 1095-1112. [CrossRef]

8. Nasello, C.; Armenio, V. A new small drifter for shallow water basins: Application to the study of surface currents in the Muggia Bay (Italy). J. Sens. 2016. [CrossRef] 
9. Young, I.R.; Rosenthal, W.; Ziemer, F. A three-dimensional analysis of marine radar images for the determination of ocean wave directionality and surface currents. J. Geophys. Res. 1985, 90, 1049-1059. [CrossRef]

10. Gangeskar, R. Ocean current estimated from X-band radar sea surface images. IEEE Trans. Geosci. Remote Sens. 2002, 40, 783-792. [CrossRef]

11. Senet, C.M.; Seemann, J.; Ziemer, F. The near-surface current velocity determined from image sequences of the sea surface. IEEE Trans. Geosci. Remote Sens. 2001, 39, 492-505. [CrossRef]

12. Senet, C.M.; Seemann, J.; Flampouris, S.; Ziemer, F. Determination of bathymetric and current maps by the method DiSC based on the analysis of nautical X-band radar image sequences of the sea surface (November 2007). IEEE Trans. Geosci. Remote Sens. 2008, 46, 2267-2279. [CrossRef]

13. Shen, C.; Huang, W.; Gill, E.W.; Carrasco, R.; Horstmann, J. An algorithm for surface current retrieval from X-band marine radar images. Remote Sens. 2015, 7, 7753-7767. [CrossRef]

14. Serafino, F.; Lugni, C.; Soldovieri, F. A novel strategy for the surface current determination from marine X-band radar data. IEEE Geosci. Remote Sens. Lett. 2010, 7, 231-235. [CrossRef]

15. Huang, W.; Gill, E. Surface current measurement under low sea state using dual polarized X-band nautical radar. IEEE J. Sel. Top. Appl. Earth Obs. Remote Sens. 2012, 5, 1868-1873. [CrossRef]

16. Serafino, F.; Lugni, C.; Ludeno, G.; Arturi, D.; Uttieri, M.; Buonocore, B.; Zambianchi, E.; Budillon, G.; Soldovieri, F. REMOCEAN: A flexible X-band radar system for sea-state monitoring and surface current estimation. Geosci. Remote Sens. Lett. 2012, 9, 822-826. [CrossRef]

17. Plant, W.J.; Keller, W.C. Evidence of Bragg scattering in microwave Doppler spectra of sea return. J. Geophys. Res. 1990, 95, 16299-16310. [CrossRef]

18. Lee, P.H.Y.; Barter, J.D.; Beach, K.L.; Hindman, C.L.; Lade, B.M.; Rungaldier, H.; Shelton, J.C.; Williams, A.B.; Yee, R.; Yuen, H.C. X-Band microwave Backscattering from ocean waves. J. Geophys. Res. 1995, 100, 2591-2611. [CrossRef]

19. Wenzel, L.B. Electromagnetic scattering from the sea at low grazing angles. In Surface Waves and Fluxes; Lewis, B.W., Ed.; Kluwer Academic: Norwell, MA, USA, 1990; pp. 41-108.

20. Ludeno, G.; Reale, F.; Dentale, F.; Pugliese, C.E.; Natale, A.; Soldovieri, F.; Serafino, F. An X-band radar system for bathymetry and wave field analysis in a Harbour area. Sensors 2015, 15, 1691-1707. [CrossRef] [PubMed]

21. Hessner, K.; Reichert, K.; Borge, J.C.N.; Stevens, C.L.; Smith, M.J. High-resolution X-band radar measurements of currents, bathymetry and sea state in highly inhomogeneous coastal areas. Ocean. Dyn. 2014, 64, 989-998. [CrossRef]

22. Ludeno, G.; Brandini, C.; Lugni, C.; Arturi, D.; Natale, A.; Soldovieri, F.; Gozzini, B.; Serafino, F. Remocean system for the detection of the reflected waves from the costa concordia ship wreck. IEEE J. Sel. Top. Appl. Earth Obs. Remote Sens. 2014, 7, 3011-3018. [CrossRef]

23. Ludeno, G.; Flampouris, S.; Lugni, C.; Soldovieri, F.; Serafino, F. A novel approach based on marine radar data analysis for high resolution bathymetry map generation. IEEE Geosci. Remote Sens. Lett. 2014, 11, 234-238. [CrossRef]

24. Nieto Borge, J.C.; Rodriguez, R.G.; Hessner, K.; Gonzales, I.P. Inversion of marine radar images for surface wave analysis. J. Atmos. Ocean. Technol. 2004, 21, 1291-1300. [CrossRef]

(C) 2016 by the authors; licensee MDPI, Basel, Switzerland. This article is an open access article distributed under the terms and conditions of the Creative Commons Attribution (CC-BY) license (http://creativecommons.org/licenses/by/4.0/). 